\title{
Clinical and Radiographic Assessment of Reasons for Replacement of Metal- Ceramic Fixed Dental Prostheses in Patients Referring to Dental School
}

\author{
Roa'a Al Refai ${ }^{1}$, Samah Saker ${ }^{2}$ \\ ${ }^{1}$ School of Dentistry, Taibah University, KSA \\ ${ }^{2}$ Associate Professor, Fixed prosthodontics Department, Faculty of Dentistry, Mansoura University, Egypt \\ Correspondence: \\ Faculty of Dentistry \\ Fixed Prosthodontics Department \\ Mansoura, Egypt \\ samah_saker@hotmail.com
}

\begin{abstract}
Al Refai R, Saker S. Clinical and Radiographic Assessment of Reasons for Replacement of Metal- Ceramic Fixed Dental Prostheses in Patients Referring to Dental School. J Clin Exp Dent. 2018;10(1):e75-80. http://www.medicinaoral.com/odo/volumenes/v10i1/jcedv10i1p75.pdf
\end{abstract}

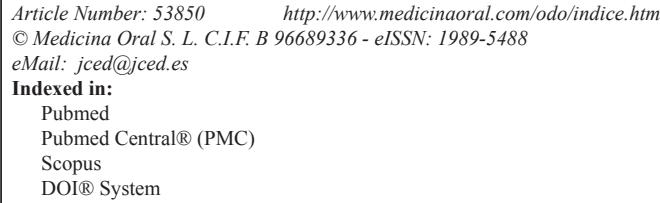

\begin{abstract}
Background: The expected length of service and reasons for fixed dental prostheses (FDPs) replacement are a frequent inquiry by patients while the answers were mainly based on studies reports that was conducted outside the middle east region. This clinical and radiographic survey was constructed to assess and survey clinically and radiographically the reasons of replacement of metal-ceramic fixed dental prostheses, amongst patients reporting at dental school in Taibah University.

Material and Methods: Between January and May 2016, 151 patients were recruited for this study. Interview (include questions pertained to the length of service of the prosthesis, the nature of complaint as told by patient in her own words), clinical examination, intra-oral photographs, and periapical radiographs, were done by the researchers. The parameters assessed were secondary caries, open margins, loss of retention, failure of endodontic treatment of the abutment and periodontal diseases.

Results: A total number of 249 failed fixed dental prostheses were evaluated. Of which 180 (39.7\%) were single crowns, $159(35.0 \%)$ were retainers and $117(25.8 \%)$ were pontics in 69 fixed partial denture. The most common reason for replacement of fixed restorations was periodontal diseases affecting $92.8 \%$ of all types' restorations, followed by defective margin in $90.4 \%$ of examined restoration, poor aesthetic in $88 \%$ of restorations, while periapical involvement was found in $85.5 \%$ of fixed dental prosthesis. The survival rates of fixed prostheses were not predictable, and no association was found between number of years in service and the number of restorations.

Conclusions: The most common reasons for replacing single unit fixed dental prostheses are periodontal diseases and periapical involvement, while defective margins and poor aesthetic mainly associated with multi-unit fixed dental prostheses.
\end{abstract}

Key words: Failure, Fixed dental prosthesis, Survival, Replacement. 


\section{Introduction}

Replacing missing teeth by means of fixed dental prosthesis is a very common treatment modality in dentistry. Fixed dental prosthesis provides satisfaction for the patient and the dentist due to its stability, retention and availability. Rational for replacing missing teeth by fixed prostheses is to improve patient comfort and increase mastication efficiency, maintain the health and integrity of the remaining alveolar ridge, and elevate the patient's psychological status (1-3).

To achieve such criteria, multiple factors must be kept in mind while planning and designing fixed prosthesis, starting with proper case selection, treatment planning, and considering all biological, mechanical and esthetic factors before beginning this way of treatment. Giving attention to all aspects mentioned above will lead to better result with favourable longevity of the prosthesis. Otherwise, failure and clinical complications might be a possibility (2). A good knowledge about these complications will be of great value for clinicians to establish a treatment plan, design and choose the right material for the patient. And will be helpful for the success of the prosthesis to reach optimum satisfaction (3).

A complication has been defined as "a secondary disease or condition developing in the course of a primary disease or condition." Even though complications could be a sign that clinical failure has occurred, but this is not always true. Complications mostly are conditions that occur either during or after an appropriate fixed prosthodontic treatment have been performed $(4,5)$.

It is confirmed in many literature, that various clinical complications were responsible for failure of fixed dental prosthesis, although the use of specific clinical, radiographic, and technical measures may have improved the length of service for fixed prosthesis. For example, removal of pre-existing restoration on the abutment, increase the percentage of gold in the alloy, placing the margin of the restoration coronal to the gingival crest, and periapical radiograph was taken prior to cementation to insure fitting of proximal margin. However, the main cause remained the same over the past years, which is dental caries, occurring in (38\%) of patients (6).

Walton et al., reported that the mean length of service of all prosthesis evaluated in the study was 8 years. Dental caries was the most observed cause of failure, affecting $22 \%$ of the units failed and leading to the necessity for replacement (7).

Other causes of failures include poor aesthetics, technical problems (fractures of the fixed connector, porcelain fractures, wear of occlusal surfaces), failure of root canal treatment of the abutment teeth, and periodontal diseases (8-18).

Now it is important to screen the recent patterns of changes, and decide the particular reasons of failure which necessitate replacement, to provide dentists with profita- ble information for prognosis and avoiding the common prosthodontics complications.

As the metal- ceramic fixed dental prostheses still used for teeth replacement in Arabic countries as a result of socio-economic factors, it's important to monitor and assess complications correlated with failure of metal ceramic fixed dental prostheses. This clinical and radiographic survey was constructed to assess and survey clinically and radiographically the reasons of replacement of fixed dental prostheses, amongst patients reporting at dental school in Taibah University and to assess the survival rates of FDPs in patient reported in dental clinics at Taibah University.

\section{Material and Methods}

This is a retrospective observational descriptive cross sectional study. 151 Patients were recruited for this study with an age range between 20 to 60 years. They were examined between January and May 2016. This study was approved by the Ethics committee of Taibah University(TDU-REC). All the participants included in the study provided written informed consent before participation. The patients were Interviewed (include questions pertained to the length of service of the prosthesis, the nature of complaint as told by patient in her own words), clinically examined (using dental mirror, explorer, tweezer and periodontal probe), intra-oral photographs (using Carestream intra-oral camera or Canon D450 SLR) and periapical radiographs (using Carestream digital radiograph system), were taken. The parameters assessed were open margins, loss of retention, periodontal diseases, secondary caries and failure of endodontic treatment of the abutment.

FDPs failure classifications were based on those reported by Walton et al.(19) (Table 1).

-Data collection and analysis

Data were collected during clinical examination by researcher and entered using R4 system (which is used in the clinics), then coded and entered into Microsoft excel software. Data was analysed by Statistical Package for the Social Sciences (SPSS). The chi (x2) criterion was used to evaluate qualitative data. The level of significance of 0.05 is chosen to assess the statistical hypotheses.

\section{Results}

A total number of 151 patients with failed fixed dental prosthesis were examined in two months. Total number of failed fixed dental prosthesis was 249 , containing 453 units. Of which 180 (39.7\%) were single crowns, 156 (34.4\%) were retainers and $117(25.8 \%)$ were pontics in 69 fixed partial denture. The most usual abutments were canines in maxillary arch and molars in mandibular arch.

The most common reason for replacement of multi-unit fixed dental prostheses were periodontal diseases affec- 
Table 1: Criteria of the failed fixed dental prostheses.

\begin{tabular}{|c|c|}
\hline \multicolumn{2}{|c|}{ The most common reasons for fixed dental prostheses replacement } \\
\hline Secondary/ recurrent caries & Caries detected at the margins of FDPs. \\
\hline Periodontal reasons & $\begin{array}{l}\text { Loss of periodontal support, gingival inflammation } \\
\text { around restoration and mobility of the abutment. }\end{array}$ \\
\hline Fracture of the restoration/s & Fracture of any part of the FDPs. \\
\hline Tooth fracture & Any form of abutment tooth fracture. \\
\hline Aesthetics & May include gingival recession exposing FDP. \\
\hline Endodontic reasons & $\begin{array}{c}\text { Endodontic reasons that lead to the need for restoration } \\
\text { replacement }\end{array}$ \\
\hline Unacceptable marginal adaptation & $\begin{array}{c}\text { FDPs with degraded or poor margins but without } \\
\text { secondary caries should be recorded in this category of } \\
\text { failure. }\end{array}$ \\
\hline
\end{tabular}

ting $92.8 \%$ of restorations, followed by defective margin in $90.4 \%$ of examined restoration, poor esthetic in $88 \%$ of restorations, while periapical involvement was found in $85.5 \%$ of examined fixed dental prosthesis. While caries and periapical involvement were mainly associated with crowns and the difference was statistically significant $(p=0.000)$. On the other hand, worn porcelain and loss of retention were mainly associated with fixed partial denture, the difference was statistically significant $(p=0,001)$, (Table 2, Figs 1-3.)
The Mean length of service of single and multi unit fixed dental prostheses were presented in Tables 3,4.

There is no correlation between years in service and the survival of restoration; it mainly depends on the marginal fitting of the restoration, quality of root canal treatment under restoration, maintenance and recall visits.

\section{Discussion}

This study was conducted to investigate the reasons of failure of metal-ceramic fixed dental prostheses, and to

Table 2: Reasons for replacement of fixed dental prostheses.

\begin{tabular}{|c|c|c|c|}
\hline & \multicolumn{2}{|c|}{ No. and (percentage of failed units\%) } & $p$ value \\
\hline Biological problems & Crown & FPD & \\
\hline Caries & $72(40 \%)$ & $12(17.4 \%)$ & 0.05 \\
\hline Periodontal disease/mobility & $168(93.3 \%)$ & $63(91.3 \%)$ & \\
\hline Periapical involvement & $171(95 \%)$ & $42(60.9 \%)$ & 0.000 \\
\hline Fractured tooth/root & $3(1.7 \%)$ & $3(4.3 \%)$ & \\
\hline Mechanical problems & & & \\
\hline Defective margin & $165(91.7 \%)$ & $60(87 \%)$ & \\
\hline Connector fracture & - & $3(4.3 \%)$ & \\
\hline Worn/lost porcelain & 0 & $12(17.4 \%)$ & 0.003 \\
\hline Looseness/poor retention & $6(3.3 \%)$ & $12(17.4 \%)$ & 0.081 \\
\hline Poor esthetic & $159(88.3 \%)$ & $60(87 \%)$ & \\
\hline
\end{tabular}




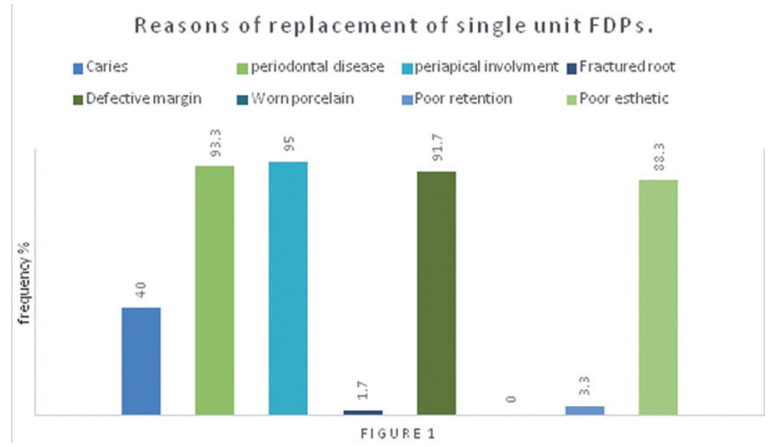

Fig. 1: Reasons of replacement of single- unit FDPs.

Reasons of replacement of multi-unit FPDS.

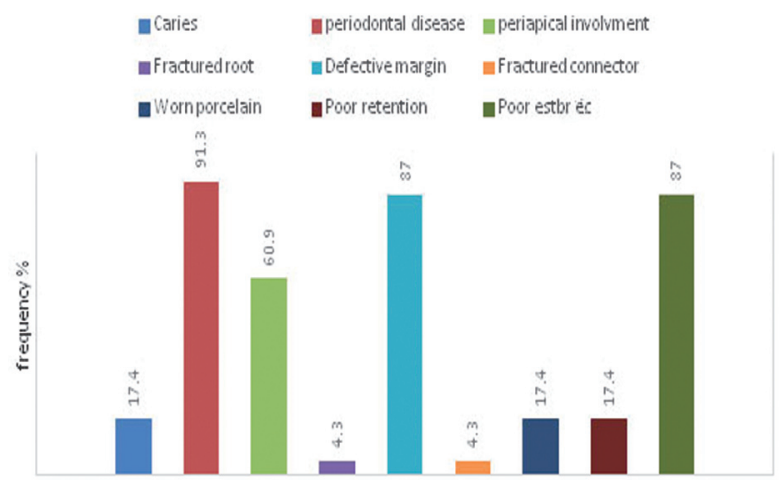

Fig. 2: Reasons of replacement of multi-unit FDPs.

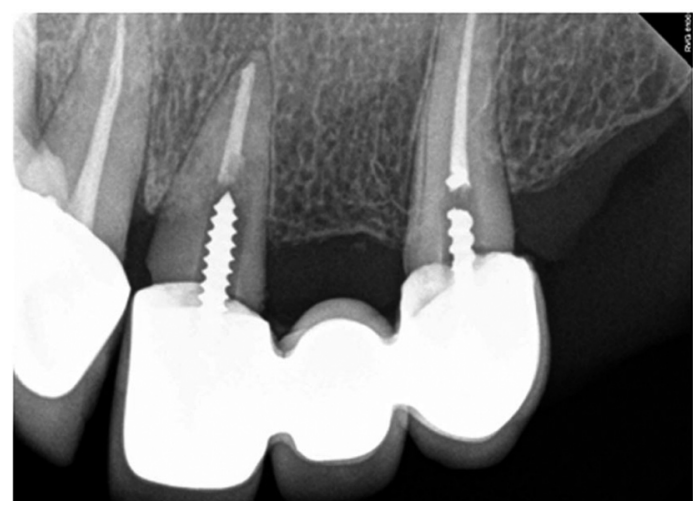

Fig. 3: Radiographic picture of a failed FDP as a result of failed posts.

failure of single unit fixed dental prostheses is due to caries, while porcelain fracture and loss are more significant in patient with multi unit FDPs.

Several risk factors may have influenced the occurrence of dental caries in association with fixed dental prostheses, comprise existing dental caries, heavily restored dentition, the size of marginal gap, home hygiene, and frequency of professional prophylaxis (20-22).

Fixed dental prostheses may affect the conditions of periodontal tissues, the incidance of caries and the amount of stress on abutment teeth (20-24).

Table 3: Mean Length of service of fixed crown.

\begin{tabular}{|c|c|c|}
\hline Duration of service in years & No. of single unit FDP & Percentage\% \\
\hline 1 & 10 & $5.5 \%$ \\
2 & 24 & $13.3 \%$ \\
3 & 29 & $16 \%$ \\
4 & 43 & $24 \%$ \\
5 & 33 & $18.3 \%$ \\
6 & 22 & $12.3 \%$ \\
7 & 12 & $6.6 \%$ \\
& 7 & $4 \%$ \\
Total & 180 & $100 \%$ \\
\hline
\end{tabular}

assess the survival rates of FDPs in patient reported in dental clinics at Taibah University.

The result of this study revealed that, the major cause of single unit FDPs failure resulted from dental caries and periapical involvement, this findings was supported by the findings of Goodacre et al. (3) and Walton et al., $(7,19,20)$ who reported that, the most common cause of
Radiographs may be helpful in evaluating interproximal margins between abutments,

as the clinical evaluation is often difficult. Although radiographs are two-dimensional images, they may provide enhanced analysis of interproximal marginal adaptation when combined with clinical evaluation.

Regarding the survival rates and longevity of the exa- 
Table 4: Mean Length of service of FPDs.

\begin{tabular}{|c|c|c|}
\hline Duration of service in years & No. of multi unit FPD & Percentage\% \\
\hline 1 & 1 & $1.4 \%$ \\
2.5 & 3 & $4.3 \%$ \\
3 & 11 & $15.9 \%$ \\
4 & 15 & $21.7 \%$ \\
5 & 16 & $23.1 \%$ \\
6 & 13 & $18.8 \%$ \\
7 & 5 & $7.2 \%$ \\
Total & 5 & $7.2 \%$ \\
& 69 & $100 \%$ \\
\hline
\end{tabular}

mined FDPs, there was no correlation between the number of year in service and survivability of FDPs. These results are similar to the finding of Libby et al., as they concluded that the number of years in service provided no information on predictability of failure for FDPs (6). Possible limitations of the study might be that the place of initial construction was not included during obtaining data, which could be significant as different dentists and technicians with varying skills have operated on the patients. Another issue is single study site, as it was difficult for the researcher to collect information, examine and evaluate patients in other centres.

Recommendation: Investigations of the initial reasons of placement of fixed dental prosthesis is recommended, as there were some cases of no reasonable cause of placement of restoration in the first place. Future studies should take the place of construction of the prosthesis in consideration (governmental services, private centres, Universities clinics).

\section{Conclusions}

The most common reasons for replacing single-unit FDPs are periodontal diseases and periapical involvement, while defective margins and poor esthetic mainly associated with multi-unit FDPs.

\section{References}

1. Hochman N, Mitelman L, Hadani PE, Zalkind M. A clinical and radiographic evaluation of fixed partial dentures (FPDs) prepared by dental school students: a retrospective study. J Oral Rehabil. 2003;30:165-70.

2. Manappallil JJ. Classification system for conventional crown and fixed partial denture failures. J Prosthet Dent. 2008;99:293-8.

3. Goodacre CJ, Bernal G, Rungcharassaeng K, Kan JY. Clinical complications in fixed prosthodontics. J Prosthet Dent. 2003;90:31-41.

4. Bart I, Dobler B, Schmidlin K, Zwahlen M, Salvi GE, Lang NP, Bragger U. Complication and failure rates of tooth-supported fixed dental prostheses after 7 to 19 years in function. Int J Prosthodont. 2012;25:360-7.
5. Sailer I, Makarov NA, Thoma DS, Zwahlen M, Pjetursson BE. All-ceramic or metal-ceramic tooth-supported fixed dental prostheses (FDPs)? A systematic review of the survival and complication rates. Part I: Single crowns (SCs). Dent Mater. 2015;31:603-23.

6. Libby G, Arcuri MR, LaVelle WE, Hebl L. Longevity of fixed partial dentures. J Prosthet Dent. 1997;78:127-31.

7. Watson P. Longevity expectations of prosthodontic treatments for dentate andedentulous patients. Int J Prosthodont. 2003;16:66-8.

8. Pjetursson BE, Sailer I, Makarov NA, Zwahlen M, Thoma DS. All-ceramic or metal-ceramic tooth-supported fixed dental prostheses (FDPs)? Asystematic review of the survival and complication rates. Part II: Multiple-unit FDPs. Dent Mater. 2015;31:624-39.

9. Walton JN, Gardner FM, Agar JR. A survey of crown and fixed partial denture failures: Length of service and reasons for replacement. J Prosthet Dent 1986;56:416-21.

10. Lindquist E \&Karlsson S. Success rate and failures for fixed partial dentures after 20 years of service: Part I. Int J Prosthodont 1998;11:133-38.

11. Wilson NA, Whitehead SA, Mjör IA, Wilson NH. Reasons for the Placement and Replacement of Crowns in General Dental Practice. Prim Dent Care 2003;10:53-59.

12. Deligeorgi V, Mjör IA, Wilson NHF. An overview of the reasons for the placement and replacement of restorations. Prim Dent Care 2001;8:5-11.

13. Selby A. Fixed prosthodontic failure. A review and discussion of important aspects. Aust Dent J. 1994;39:150-6.

14. Valderhaug J, Jokstad A, Ambjørnsen E, Norheim PW. Assessment of the periapical and clinical status of crowned teeth over 25 years. J Dent. 1997;25:97-105.

15. Glantz PO, Nilner K, Jendresen MD, Sundberg H. Quality of fixed prosthodontics after 15 years. Acta Odontol Scand. 1993;51:247-52.

16. Ioannidis G, paschaalidis T, Petridis HP. The influence of age on tooth supported prosthetic restoration longevity. A systemic review. J Dent. 2010;38:173-81.

17. Tan K, Pjetursson BE, Lang NP, Chan ESY. A systematic review of the survival and complication rates of fixed partial dentures (FPDs) after an observation period of at least 5 years. III. Conventional FPDs.Clin. Ora 1 Impl Res 2004;15:654-66.

18. Burke FJT, Cheung SW, Mjör IA, Wilson NHF. Restoration longevity and the analysis of reasons for the placement and the replacement of restorations provided by vocational dental practitioners and their trainers in the United Kingdom. Quintessence Int 1999;30:234-42.

19. Walton JN, Gardner FM, Agar JR. A survey of crown and fixed partial denture failures: length of service and reasons for replacement. J Prosthet Dent 1986;56:416-21. 
20. Walton TR. An up to 15 -year longitudinal study of 515 metalceramic FPDs: Part 1. Outcome. Int J Prosthodont. 2002;15:439-45.

21. Walton TR. An up to 15-year longitudinal study of 515 metal-ceramic FPDs: Part 2. Modes of failure and influence of various clinical characteristics. Int J Prosthodont. 2003;16:177-82.

22. Holm C, Tidehag P, Tillberg A, Molin M. Longevity and quality of FPDs: a retrospective study of restorations 30, 20, and 10 years after insertion. Int J Prosthodont. 2003; 16:283-9.

23. Oginni AO. Failures related to crowns and fixed partial dentures fabricated in a Nigerian dental school. J Contemp Dent Pract. 2005;6:136-43.

24. De Backer H, Van Maele G, De Moor N, Van den Berghe L, De Boever J. A 20 -year retrospective survival study of fixed partial dentures. Int J Prosthodont. 2006;19:143-53.

\section{Conflicts of Interest}

The authors declare that they have no conflict of interest. 